\title{
Caracterização fisiológica da compatibilidade reprodutiva de ameixeira japonesa
}

\author{
Juliana de Magalhães Bandeira(1), Liane Bahr Thurow ${ }^{(1)}$, José Antonio Peters(1), \\ Maria do Carmo Bassols Raseira(2) e Valmor João Bianchi(1)
}

\begin{abstract}
(1)Universidade Federal de Pelotas, Instituto de Biologia, Departamento de Botânica, Caixa Postal 354, CEP 96010-900 Capão do Leão, RS. E-mail: bandeira_m@@hotmail.com, lianepel@yahoo.com.br, japeters1@hotmail.com, valmorjb@yahoo.com (2)Embrapa Clima Temperado, Rodovia BR 392, Km 78, Caixa Postal 403, CEP 96001-970 Pelotas, RS. E-mail: bassols@cpact.embrapa.br
\end{abstract}

Resumo - O objetivo deste trabalho foi caracterizar fisiologicamente a compatibilidade reprodutiva de seis cultivares de ameixeira japonesa (Prunus salicina), por meio da avaliação da frutificação e do crescimento do tubo polínico (CTP). A percentagem de frutificação foi determinada 40 dias após cruzamentos controlados, realizados a campo, entre seis cultivares. O grau de compatibilidade foi avaliado in vivo, para determinar o CTP. O pegamento de frutos foi muito baixo para todos os cruzamentos: máximo de $8,1 \%$, com a autopolinização de 'Reubennel'. Nos cruzamentos in vivo, o CTP apresentou variações significativas em cada genitor feminino. Os cruzamentos 'América' x 'Pluma 7' e 'Rosa Mineira' x 'Santa Rosa' foram incompatíveis, enquanto a autofecundação de 'América' e 'Pluma 7' apresentou autoincompatibilidade. Não houve frutificação, no campo, no cruzamento 'Reubennel' x 'Rosa Mineira' e nos recíprocos entre 'Rosa Mineira' e 'Amarelinha' x 'América' e 'Amarelinha', e 'Pluma 7' e 'Santa Rosa' x 'América'. No entanto, na polinização in vivo, o CTP atingiu o óvulo ou o ovário nesses cruzamentos. Apenas os cruzamentos entre 'América' x 'Pluma 7' e 'Rosa Mineira' x 'Santa Rosa' são incompatíveis, e a cultivar América é autoincompatível.

Termos para indexação: Prunus salicina, autoincompatibilidade, biologia reprodutiva, cruzamentos dirigidos, polinização in vivo.

\section{Physiological characterization of reproductive compatibility of Japanese plum}

\begin{abstract}
The objective of this work was to physiologically characterize the reproductive compatibility of six Japanese plum (Prunus salicina) cultivars by evaluating fruit set and pollen tube growth (PTG). Fruit set percentage was determined after 40 days of controlled crosses made between six cultivars, in the field. The degree of compatibility was evaluated in vivo to determine PTG. Fruit set was very low for all crosses: maximum of $8.1 \%$, with 'Reubennel' self-pollination. At in vivo crossing, PTG showed significant variations in each female parent. The crosses between 'América' x 'Pluma 7' and 'Rosa Mineira' x 'Santa Rosa' were incompatible, while the selfing of 'América' and 'Pluma 7' showed self-incompatibility. No fruit set was observed in the field in the cross 'Reubennel' x 'Rosa Mineira', and in the reciprocals between 'Rosa Mineira' and 'Amarelinha' x 'América' and 'Amarelinha', and 'Pluma 7' and 'Santa Rosa' x 'América'. However, with in vivo pollination, PTG reached the egg or the ovary in these crosses. Only crosses between 'América' x 'Pluma 7' and 'Rosa Mineira' x 'Santa Rosa' are incompatible, and América cultivar is self-incompatible.
\end{abstract}

Index terms: Prunus salicina, self-incompatibility, reproductive biology, controlled crosses, in vivo pollination.

\section{Introdução}

Entre as espécies de ameixeira, a ameixeira japonesa (Prunus salicina Lindl.) é a mais cultivada no Brasil, pois apresenta genótipos com menor exigência em frio (Revers \& Machado, 2005). Entretanto, a grande maioria das cultivares dessa espécie apresenta diferentes graus de compatibilidade reprodutiva, determinada por um loco multialélico que contém os denominados alelos-S (Takayama \& Isogai, 2005). Portanto, durante a instalação do pomar, é indicada a implantação de pelo menos uma planta polinizadora para cada quatro produtoras (Castro et al., 2008a), com compatibilidade e período de floração total ou parcialmente sincronizado (Sapir et al., 2004), para garantir a fecundação e níveis de produção economicamente aceitáveis.

O sucesso da polinização cruzada é influenciado por fatores genéticos de compatibilidade, pela ação de insetos polinizadores e por fatores ambientais (Goldway et al., 1999). Alterações em qualquer um 
desses fatores, durante o transporte e a germinação do grão de pólen até a efetiva fecundação, poderão impedir a formação dos frutos, o que pode limitar ou até mesmo inviabilizar a produção (Sanzol \& Herrero, 2001).

Em angiospermas, a velocidade de crescimento do tubo polínico (CTP) até o ovário é variável e pode levar em torno de 11 horas em Acacia retinodes Schltdl., seis dias em Banksia coccinea R.Br. e duas semanas em Eucalyptus nitens (Deane \& Maiden) (Pound et al., 2003). Em ameixeiras, o CTP também é lento, cerca de 120 horas (Carvalho, 1989). A determinação da velocidade do CTP, bem como a identificação da região do pistilo onde o CTP é interrompido, pode evidenciar o sistema e o grau de incompatibilidade atuante entre cruzamentos.

A autoincompatibilidade é um importante mecanismo reprodutivo presente na maioria das angiospermas para evitar a autofecundação, o que contribui para manter e aumentar a diversidade dentro das espécies (Zhang et al., 2009). No entanto, ela é uma das principais barreiras para programas de melhoramento genético, que buscam a obtenção de novas cultivares, e para o manejo reprodutivo dos pomares. De acordo com Bittencourt Junior et al. (2003), no sistema de autoincompatibilidade reprodutiva do tipo gametofítico, os tubos polínicos incompatíveis têm o seu desenvolvimento cessado no estilete. Essa paralisação pode ser atribuída à expressão, no pistilo, de um determinante feminino (S-RNAse) que segrega junto com os alelos-S. As proteínas resultantes da expressão desses alelos estão presentes desde a superfície das papilas estigmáticas até o ovário, mas localizam-se, principalmente, na parte superior do estilete (Schifino-Wittmann \& Dall'Agnol, 2002), onde atuam por inibição ou degradação do RNA do tubo polínico que compartilha o mesmo alelo-S do pistilo (Takayama \& Isogai, 2005).

O reconhecimento do pólen incompatível ocorre no nível de interação proteína-proteína dos dois determinantes (masculino e feminino) (Takayama \& Isogai, 2005). Como os grãos de pólen apresentam expressão independente e segregam 1:1, os cruzamentos podem ser compatíveis, quando os alelos do grão de pólen e do pistilo são diferentes; semicompatíveis, quando pelo menos um alelo-S do grão de pólen é idêntico ao do pistilo; ou totalmente incompatíveis, quando os dois alelos-S do grão de pólen são idênticos aos do pistilo (Richards, 1986).
A avaliação da compatibilidade reprodutiva da ameixeira japonesa requer polinizações controladas a campo, combinadas com análises laboratoriais, para determinar a viabilidade dos grãos de pólen (Leite \& Souza, 2003). Além disso, técnicas de microscopia permitem analisar características associadas à germinação dos tubos polínicos e suas taxas de crescimento. Assim, é possível analisar hibridações efetivas em programas de melhoramento genético, bem como elucidar características referentes à incompatibilidade reprodutiva, sem sofrer influência dos fatores ambientais.

O objetivo deste trabalho foi caracterizar fisiologicamente a compatibilidade reprodutiva de seis cultivares de ameixeira japonesa, por meio da avaliação da frutificação e do crescimento do tubo polínico.

\section{Material e Métodos}

Para as análises de caracterização fisiológica da compatibilidade, foram utilizadas seis cultivares de ameixeira japonesa como progenitores femininos: Amarelinha, América, Pluma 7, Reubennel, Rosa Mineira e Santa Rosa. As cultivares foram avaliadas no Campo Experimental da Embrapa Clima Temperado, em Pelotas, RS. As seguintes combinações de cultivares foram avaliadas com cruzamentos: América como progenitor feminino e Amarelinha, América, Pluma 7, Reubenel, Rosa Mineira, Santa Rosa e The First como progenitores masculinos; Amarelinha como progenitor feminino e Amarelinha, América, Reubennel e Rosa Mineira como masculinos; Reubennel como progenitor feminino e América, Reubennel e Rosa Mineira como masculinos; Rosa Mineira como progenitor feminino Amarelinha, América, Reubennel, Rosa Mineira e Santa Rosa como masculinos; Pluma 7 como progenitor feminino e América e Pluma 7 como masculinos; e Santa Rosa como progenitor feminino e América e Santa Rosa como masculinos.

As polinizações foram executadas no momento em que as plantas estavam em plena floração, tendo sido utilizadas 150 flores, em estádio de balão, para cada cruzamento.

Após a emasculação e a polinização das flores, os ramos foram ensacados com tecido não tecido (TNT) branco, por uma semana. A percentagem de frutificação foi determinada em relação ao número de flores polinizadas após 40 dias. Como controle, foi realizada 
a autopolinização das cultivares produtoras, nas quais os botões florais foram emasculados e polinizados com o pólen da própria cultivar.

A determinação do ponto de interrupção do CTP foi avaliada por meio da polinização in vivo e por testes de CTP, com o método de Wilson \& Brown (1957), com algumas adaptações (Carvalho, 1989). Para isso, quatro ramos de cada planta, com pelo menos dez flores em estádio de balão, foram coletados e acondicionados no laboratório, à temperatura ambiente $\left(18-20^{\circ} \mathrm{C}\right)$. As flores foram emasculadas e polinizadas manualmente com o pólen de interesse, de acordo com as combinações de cruzamentos.

Os pistilos foram coletados 120 horas após a polinização, fixados em FAA e armazenados em geladeira a $4^{\circ} \mathrm{C}$, para posterior avaliação do CTP por coloração histoquímica (Carvalho, 1989).

Após o preparo, as lâminas foram visualizadas em microscópio óptico (Carl Zeiss do Brasil Ltda., São Paulo, SP), com ocular de 10x e objetiva de 40x. Foram observadas 20 lâminas para cada combinação de cruzamento. Avaliou-se a percentagem de grãos de pólen germinados e o grau de desenvolvimento do tubo polínico, por meio da atribuição de notas de $1 \mathrm{a}$ 7 (Tabela 1), segundo classificação de Franken et al. (1988).

Nos cruzamentos realizados a campo, foi avaliada a percentagem de frutificação das 150 flores polinizadas, $\mathrm{e}$, nos cruzamentos in vivo, utilizou-se o delineamento experimental inteiramente casualizado, com quatro repetições de cinco flores. Os dados foram submetidos à análise de variância, e as médias foram comparadas pelo teste de Duncan, a 5\% de probabilidade, com o programa WinStat 2.0 (Machado \& Conceição, 2003). Os dados da variável percentagem de grãos de pólen germinados foram transformados para $(\mathrm{x} / 100)^{0,5}$, e

Tabela 1. Estadios de desenvolvimento do tubo polínico no pistilo das cultivares de ameixeira japonesa (Prunus salicina) polinizadas in vivo ${ }^{(1)}$.

\begin{tabular}{ll}
\hline Estadio & Desenvolvimento do tubo polínico \\
\hline 1 & Tubo polínico no estigma, sem penetrar no estilete \\
3 & Tubo polínico no primeiro terço do estilete \\
4 & Tubo polínico no segundo terço do estilete \\
5 & Tubo polínico no terceiro terço do estilete \\
6 & Tubo polínico no interior do ovário \\
7 & Tubo polínico próximo ao óvulo \\
Tubo polínico no óvulo
\end{tabular}

${ }^{(1)}$ Adaptado de Franken et al. (1988). os graus de desenvolvimento do tubo polínico foram transformados para log (x).

\section{Resultados e Discussão}

A maior percentagem de frutificação foi obtida na autopolinização da cultivar Reubennel (8,41\%), enquanto os demais cruzamentos apresentaram valores inferiores a 3,5\% (Tabela 2). De acordo com Van Tonder \& Bester (1979), na polinização livre, apenas $5 \%$ de frutificação seria suficiente para assegurar boa produção comercial em cultivares de ameixeira. Esses autores constataram, em regiões tipicamente de

Tabela 2. Percentagem de frutificação dos cruzamentos controlados, realizados a campo, nos pomares de ameixeira japonesa (Prunus salicina), e percentagem de grãos de pólen germinados no estigma das flores após 120 horas da polinização in vivo ${ }^{(1)}$.

\begin{tabular}{|c|c|c|}
\hline \multirow[t]{2}{*}{ Genitor masculino } & Frutificação & Pólen germinado no estigma \\
\hline & \multicolumn{2}{|c|}{ 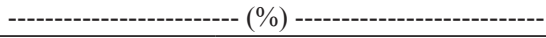 } \\
\hline & \multicolumn{2}{|c|}{ 'América' como genitor feminino } \\
\hline 'Amarelinha' & 0,63 & $100,00 \mathrm{a}$ \\
\hline 'América' & 0,00 & $67,86 \mathrm{bc}$ \\
\hline 'Pluma 7' & 0,00 & $90,65 \mathrm{ab}$ \\
\hline 'Reubennel' & 2,44 & $60,00 \mathrm{c}$ \\
\hline 'Rosa Mineira' & 0,66 & $71,61 b c$ \\
\hline 'Santa Rosa' & 1,33 & $70,56 \mathrm{bc}$ \\
\hline \multirow[t]{2}{*}{ 'The First' } & 0,00 & $84,23 \mathrm{abc}$ \\
\hline & \multicolumn{2}{|c|}{ 'Amarelinha' como genitor feminino } \\
\hline 'Amarelinha' & 0,00 & $97,69 \mathrm{ab}$ \\
\hline 'América' & 0,00 & $88,90 \mathrm{~b}$ \\
\hline 'Reubennel' & 3,47 & $97,27 \mathrm{ab}$ \\
\hline \multirow[t]{2}{*}{ 'Rosa Mineira' } & 1,28 & $100,00 \mathrm{a}$ \\
\hline & \multicolumn{2}{|c|}{ 'Reubennel' como genitor feminino } \\
\hline 'América' & 0,68 & $94,66 \mathrm{a}$ \\
\hline 'Reubennel' & 8,41 & $80,46 b$ \\
\hline \multirow[t]{2}{*}{ 'Rosa Mineira' } & 0,00 & $40,23 \mathrm{c}$ \\
\hline & \multicolumn{2}{|c|}{ 'Rosa Mineira' como genitor feminino } \\
\hline 'Amarelinha' & 0,00 & $100,00 \mathrm{a}$ \\
\hline 'América' & 0,00 & $89,29 a$ \\
\hline 'Reubennel' & 3,47 & $100,00 \mathrm{a}$ \\
\hline 'Rosa Mineira' & 1,28 & $100,00 \mathrm{a}$ \\
\hline \multirow[t]{2}{*}{ 'Santa Rosa'(2) } & - & $21,67 \mathrm{~b}$ \\
\hline & \multicolumn{2}{|c|}{ 'Pluma 7' como genitor feminino } \\
\hline 'América' & 0,00 & $71,42 \mathrm{a}$ \\
\hline \multirow[t]{2}{*}{ 'Pluma 7' } & 0,00 & $85,00 \mathrm{a}$ \\
\hline & \multicolumn{2}{|c|}{ 'Santa Rosa' como genitor feminino } \\
\hline 'América' & 0,00 & $80,14 \mathrm{a}$ \\
\hline 'Santa Rosa' & 0,00 & $70,56 \mathrm{a}$ \\
\hline
\end{tabular}


clima temperado, onde a floração é mais abundante e uniforme do que no Brasil, que 'Reubennel' é mais adaptada a condições de inverno ameno do que as demais cultivares e, além disso, não é totalmente autoincompatível. No entanto, quando a floração nessa cultivar não é abundante, o uso de plantas polinizadoras é fundamental.

Com a autofecundação, a frutificação somente ocorreu nas cultivares Reubennel $(8,41 \%)$ e Rosa Mineira (1,28\%) (Tabela 2). Esses resultados estão de acordo com os relatos de Raseira (2003), de que ambas as cultivares são moderadamente compatíveis e podem produzir uma boa colheita comercial, mesmo sem a utilização de polinizadoras, desde que haja florescimento abundante e condições meteorológicas favoráveis.

Apesar de não ter havido frutificação em alguns cruzamentos realizados a campo, não é possível afirmar que houve incompatibilidade reprodutiva entre as cultivares, uma vez que inúmeros fatores ambientais podem ocasionar variações na polinização efetiva, do momento do florescimento até a polinização (Barbosa, 2006). Entre esses fatores, a emasculação realizada durante os cruzamentos dirigidos pode causar dano no pistilo, em virtude da delicada constituição das flores de ameixeira (Thiele \& Strydom, 1964).

Segundo Nava et al. (2009), a injúria é um importante fator associado à baixa frutificação e tem sido registrada regularmente em pomares brasileiros de ameixeiras, pessegueiros e nectarineiras, principalmente na região Sul do Brasil. Isso ocorre em razão da antecipação do florescimento causada pela elevada temperatura durante o período que antecede a floração, o que resulta no retardamento do desenvolvimento do gametófito feminino e na formação de anomalias dos gametófitos masculinos.

A baixa taxa de frutificação, nos cruzamentos controlados, também foi evidenciada em outros trabalhos de hibridação controlada realizados nos pomares de ameixeira da Embrapa Clima Temperado, Pelotas, RS, na safra 2007/2008. Embora esses dados não tenham sido quantificados, esse evento foi atribuído ao rápido aquecimento no final do inverno e à geada tardia no final de setembro de 2007, que causou a queima de botões e primórdios florais. $\mathrm{O}$ estresse por condições meteorológicas desfavoráveis pode reduzir a viabilidade do grão de pólen, bem como a produção de sacos embrionários viáveis, o que resulta na falta de sincronia no processo de fecundação e na redução da frutificação.

Em relação aos cruzamentos in vivo, realizados em laboratório, foi observada elevada percentagem de grãos de pólen germinados $(70-100 \%)$ na região estigmática do pistilo (Tabela 2), o que indica que os grãos de pólen estavam viáveis.

Para a percentagem de grãos de pólen germinados na região estigmática, houve diferença apenas entre os cruzamentos realizados com os genitores femininos 'América', 'Amarelinha', 'Reubennel' e 'Rosa Mineira'. Não foram observadas diferenças nos cruzamentos nas cultivares Pluma 7 e Santa Rosa, com média de 78,20 e $75,35 \%$ dos grãos de pólen germinados, respectivamente (Tabela 2 ).

Na polinização in vivo, houve diferença significativa quanto ao grau de desenvolvimento do tubo polínico, em cada genitor feminino (Figura 1). Nos cruzamentos realizados in vivo, não houve penetração do tubo polínico no óvulo, apenas crescimento próximo a ele. Para verificar se as cultivares apresentam incompatibilidade reprodutiva do tipo gametofítica, por meio do CTP, foi observada a capacidade de os tubos polínicos ultrapassarem a barreira da incompatibilidade, que se localiza no terço médio do estilete (Schifino-Wittmann \& Dall'Agnol, 2002). Nesse sistema de incompatibilidade, quando os alelos-S do gametófito feminino (pistilo) e masculino (grão de pólen) são diferentes, ocorre a síntese de um polissacarídeo (calose) na zona nuclear e de vacuolação do tubo polínico, que o protege e permite o seu desenvolvimento para que ocorra a fecundação. Contudo, quando os alelos são iguais, ocorre deposição irregular de calose, o que causa engrossamento da extremidade dos tubos polínicos, com consequente bloqueio da sua passagem, o que pode resultar no rompimento dos tubos e na inibição ou a paralisação do seu desenvolvimento (Shifino-Wittmann \& Dall'Agnol, 2002).

Segundo Zhang et al. (2009), além das alterações morfoanatômicas observadas no presente trabalho, nos cruzamentos compatíveis a S-RNase secretada pelas células do estigma sofre endocitose para o interior do tubo polínico, onde é ubiquitinada, após ligar-se a proteínas de ligação, e armazenada inativamente no vacúolo das células do tubo polínico. Nos cruzamentos incompatíveis, o complexo formado entre a S-RNase e as proteínas de ligação é considerado inativo, o que impede 
a ubiquitinação. Esse complexo será liberado no citosol do tubo polínico, onde apresenta efeitos citotóxicos, o que interrompe seu alongamento, ao promover a quebra do DNA ribossomal, e impede a formação de moléculas necessárias para a divisão celular.

Associado a esses eventos, ocorre o acúmulo excessivo de $\mathrm{Ca}^{2+}$ nos tubos polínicos, o que, provavelmente, está relacionado à morte programada das células, decorrente da fragmentação do DNA nuclear e da perda do citocromo C. De acordo com Thomas \& Franklin-Tong (2004), esse processo representa uma das etapas das diversas reações em cascata que causam a incompatibilidade reprodutiva.

Todas as cultivares utilizadas na polinização da cultivar América (Figura 1) atingiram o óvulo após 120 horas, exceto na autopolinização, em que o CTP foi interrompido no terço médio do estilete (estádio 3), com 55\% de incidência. As cultivares Pluma 7 e Santa Rosa atingiram $40 \%$ de incidência do tubo polínico no estádio 3, mas apresentaram CTP até os estádios 4 (último terço do estilete) e 5 (no ovário), respectivamente, o que indica capacidade de fecundação da cultivar América por essas cultivares. Porém, como o CTP foi mais lento, provavelmente seria necessário mais tempo para que os tubos polínicos chegassem ao óvulo, nessas cultivares.

A velocidade de CTP é de extrema importância para o sucesso reprodutivo da planta, pois quanto mais rápido for, menores serão os efeitos dos fatores externos, que podem provocar a abscisão do estilete antes da fecundação (Carvalho, 1989). Segundo Silveira (2008), os cruzamentos incompatíveis apresentam CTP mais lento que os compatíveis.

De acordo com Raseira (2003) e Castro et al. (2008b), as cultivares polinizadoras recomendadas para 'América' são Reubennel e Rosa Mineira. Contudo, no presente trabalho, verificou-se que 'Amarelinha' e 'The First' também podem ser utilizadas como possíveis polinizadoras, em trabalhos de melhoramento e em pomares comerciais. A primeira cultivar é considerada de floração precoce, ou seja, floresce do início de agosto a meados de setembro, enquanto a segunda é considerada de floração mediana, pois apresenta floração precoce em anos frios e floração tardia quando o frio é insuficiente para superação da dormência antecipada (Carvalho, 1989).

As cultivares Santa Rosa e América são consideradas autoincompatíveis (Raseira, 2003; Mota et al., 2010). No entanto, no cruzamento 'Santa Rosa' x 'América', houve $60 \%$ de incidência do tubo polínico no grau 6 , o que indica compatibilidade entre as cultivares (Figura 1). Porém, a reciproca não se mostrou verdadeira, ou seja, no cruzamento 'América' x 'Santa Rosa', apenas $40 \%$ dos tubos polínicos estavam no grau 3, com baixa incidência de CTP no grau 5 (Figura 1). Essas diferenças na incidência do CTP podem estar relacionadas às diferenças na maturidade dos pistilos no momento da polinização, que podem estar mais receptivos na cultivar Santa Rosa.

Esse resultado também pode ser considerado uma característica de cruzamento semicompatível, em que pelo menos um dos alelos-S do genitor masculino, nesse caso 'Santa Rosa', apresenta um alelo-S diferente dos tecidos diploides dos pistilos do genitor feminino. Assim, aproximadamente $50 \%$ dos grãos de pólen são capazes de germinar e fecundar o óvulo, enquanto os outros $50 \%$ terão o CTP interrompido no estilete. Segundo Mota et al. (2010), que realizaram análises moleculares e sequenciamento dos alelos-S de algumas cultivares de ameixeira japonesa, como Santa Rosa e América, isso ocorre porque as cultivares apresentam um alelo idêntico, denominado de alelo $S^{c}$ ou $S^{4}$.

No presente trabalho, a cultivar América pôde ser considerada boa polinizadora da 'Santa Rosa', o que seria de grande valia já que esta última apresenta o alelo $S^{e}$ (Mota et al., 2010), o qual determina um certo grau de autofertilidade (Beppu et al., 2002, 2010). Portanto, é possível que a segregação desse alelo promova a quebra parcial da autoincompatibilidade em cultivares autoincompatíveis, como a América. Nos trabalhos de Beppu et al. (2005) e Guerra et al. (2009), observouse que os híbridos descendentes da cultivar Santa Rosa e portadores do alelo $S^{e}$ foram parcialmente autocompatíveis.

Quando 'Pluma 7' foi utilizada como genitor feminino, os grãos de pólen da cultivar América apresentaram CTP até o grau 6, com maior incidência no grau 5 (45\%). Na autopolinização, $50 \%$ dos tubos polínicos se desenvolveram apenas até o grau 3, o que pode ser caracterizado como autoincompatibilidade reprodutiva (Figura 1). Entretanto, esses resultados não estão de acordo com os obtidos por Raseira (2003), em que a cultivar Pluma 7 foi considerada moderadamente autocompatível. Assim, são necessários novos estudos para comprovar esses resultados.

As cultivares utilizadas como polinizadoras da 'Amarelinha' apresentaram elevada incidência do tubo polínico próximo ao óvulo (estádio 6). Embora 
a autopolinização tenha apresentado $55 \%$ dos tubos polínicos no grau 3, parte dos tubos polínicos teve incidência no grau 5, o que indica que a cultivar é semicompatível (Figura 1). Esses resultados são indicativos de que as cultivares utilizadas no presente trabalho são compatíveis reprodutivamente com a 'Amarelinha', para uso no melhoramento, apesar de
Raseira (2003) e Castro et al. (2008b) recomendarem apenas 'Pluma 7', 'Friar' e 'Blood Plum' como polinizadoras dessa cultivar.

Os cruzamentos realizados com a ameixeira 'Rosa Mineira' apresentaram elevado CTP até o grau 6, tendo chegado a 100\% com a polinizadora 'Reubennel' e a $60 \%$ com as cultivares América, Amarelinha e com a própria
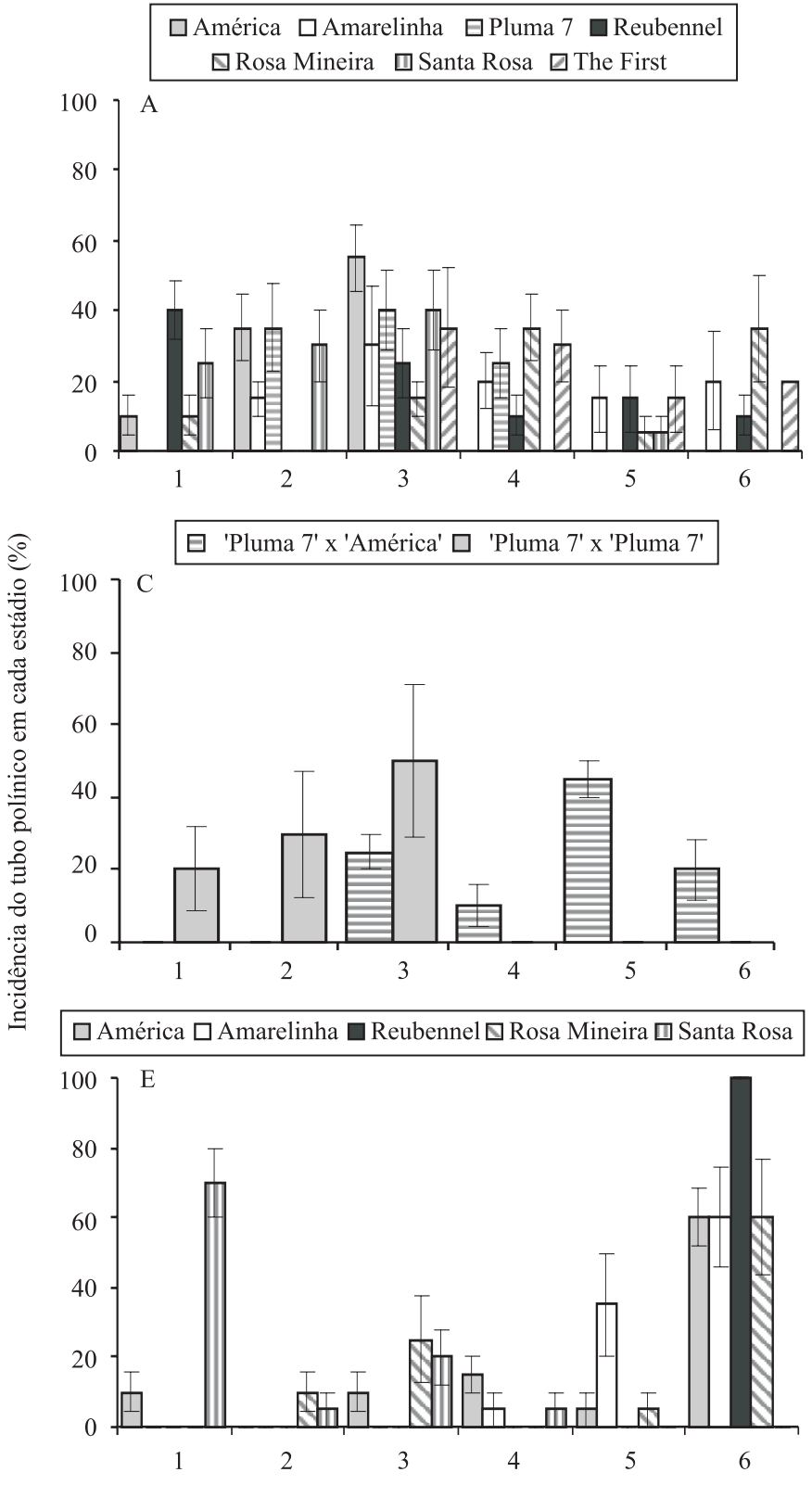

'Santa Rosa' x 'América' 四 'América' x 'Santa Rosa'
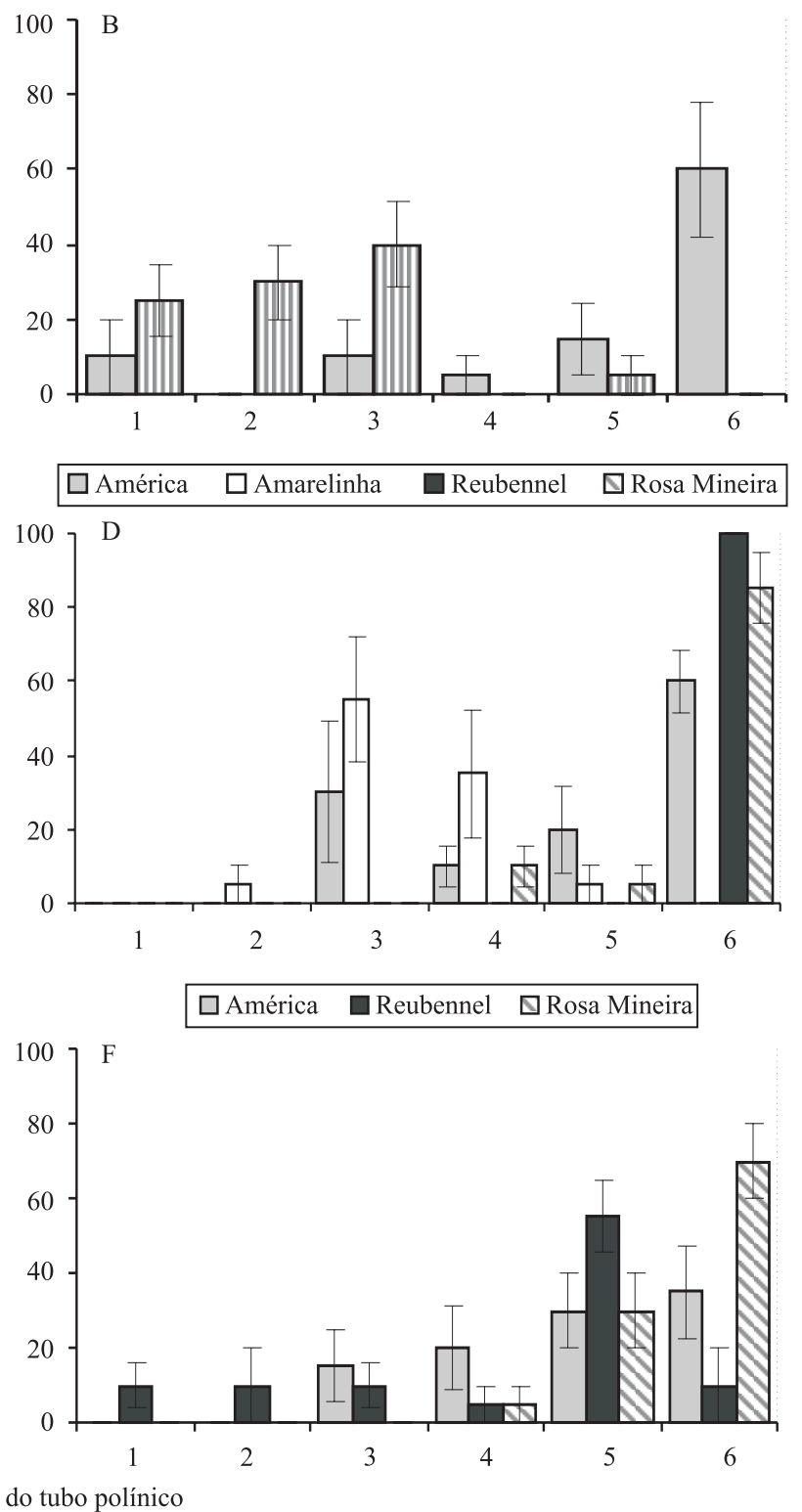

Figura 1. Percentagem de incidência do tubo polínico em cada etapa do percurso estigma-óvulo de ameixeiras japonesas (Prunus salicina), em função das polinizações controladas, realizadas in vivo, após 120 horas, e mantidas em temperatura ambiente nos cruzamentos: A, com 'América' como genitor feminino; B, recíprocos entre 'Santa Rosa' e 'América'; C, entre 'Pluma 7' x 'América' e 'Pluma 7' x 'Pluma 7'; D, com 'Amarelinha' como genitor feminino; E, com 'Rosa Mineira' como genitor feminino; e F, com 'Reubennel' como genitor feminino. As barras representam o erro-padrão da média. 
Rosa Mineira. Entretanto, no cruzamento desta cultivar com o pólen da 'Santa Rosa', houve $70 \%$ de incidência de tubos polínicos no estádio 1 e não houve CTP nos estádios 5 e 6 (Figura 1). Apesar da baixa incidência do CTP no estádio 3, os dados desse cruzamento, em específico, não são considerados conclusivos na determinação da compatibilidade, pois ambas as cultivares (Rosa Mineira e Santa Rosa) apresentam alelos-S distintos (Mota et al., 2010). Portanto, algum outro fator, entre os mencionados anteriormente, pode ter influenciado negativamente o CTP.

Todas as polinizações realizadas na cultivar Reubennel apresentaram CTP até o grau 6, mesmo com baixo percentual, como no caso de 'Reubennel' e 'América', o que indica compatibilidade reprodutiva com os genitores masculinos utilizados no presente trabalho (Figura 1).

Embora não tenha havido frutificação de alguns cruzamentos durante a polinização realizada a campo, houve CTP até o óvulo (estádio 6) ou ovário (estádio 5) na polinização in vivo, em 'Reubennel' x 'Rosa Mineira', e nos recíprocos 'Rosa Mineira' e 'Amarelinha' $x$ 'América' e 'Amarelinha', e 'Pluma 7' e 'Santa Rosa' x 'América', o que confirma a compatibilidade reprodutiva dos genótipos utilizados nos respectivos cruzamentos.

$\mathrm{Na}$ prática, a escolha de plantas polinizadoras é baseada principalmente na coincidência da floração, o que nem sempre traz resultados produtivos satisfatórios, em virtude da incompatibilidade entre cultivares. Além dos aspectos fisiológicos avaliados, é possível observar que o uso dessa estratégia associada a dados de caracterização molecular dos alelos-S facilita o entendimento do sistema reprodutivo e a escolha dos genótipos mais compatíveis, tanto para uso no melhoramento, quanto para implantação de pomares dessa espécie.

\section{Conclusões}

1. Dos cruzamentos de ameixeira japonesa avaliados, apenas os cruzamentos entre 'America' x 'Pluma' e 'Rosa Mineira' x 'Santa Rosa' apresentam incompatibilidade reprodutiva.

2. A cultivar América de ameixeira japonesa apresenta autoincompatibilidade reprodutiva.

\section{Agradecimentos}

Ao Conselho Nacional de Desenvolvimento Científico e Tecnológico, pelo apoio financeiro.

\section{Referências}

BARBOSA, W. Gulfblaze: nova opção de ameixa para o Estado de São Paulo. 2006. Disponível em: <http://www.infobibos.com/ Artigos/Ameixa/Ameixa.htm>. Acesso em: 12 maio 2011.

BEPPU, K.; KOMATSU, N.; YAMANE, H.; YAEGAKI, H.; YAMAGUCHI, M.; TAO, R; KATAOKA, I. Se-haplotype confers self-compatibility in Japanese plum (Prunus salicina Lindl.). Journal of Horticultural Science and Biotechnology, v.80, p.760-764, 2005.

BEPPU, K.; SYOGASE, K.; YAMANE, H.; TAO, R.; KATAOKA, I. Inheritance of self-compatibility conferred by the $S^{e}$-haplotype of Japanese plum and development of $\mathrm{S}^{\mathrm{e}}$-RNase gene-specific PCR primers. Journal of Horticultural Science and Biotechnology, v.85, p.215-218, 2010.

BEPPU, K.; YAMANE, H.; YAEGAKI, H.; YAMAGUCHI, M.; KATAOKA, I.; TAO, R. Diversity of S-RNase genes and S-haplotypes in Japanese plum (Prunus salicina Lindl.). The Journal of Horticultural Science and Biotechnology, v.77, p.658-664, 2002.

BITTENCOURT JUNIOR, N.S.; GIBBS, P.E.; SEMIR, J. Histological study of pos-pollination events in Spathodea Campanulata Beauv. (Bignoniaceae), a species with late-acting self-incompatibility. Annals of Botany, v.91, p.827-834, 2003.

CARVALHO, T.C.P. Comportamento de algumas cultivares de ameixeira (Prunus salicina) quanto à polinização no Rio Grande do Sul. 1989. 73p. Dissertação (Mestrado) - Universidade Federal de Pelotas, Pelotas.

CASTRO, L.A.S. de; NAKASU, B.H.; PEREIRA, J.F.M. Ameixeira: histórico e perspectivas de cultivo. Pelotas: Embrapa Clima Temperado, 2008a. 10p. (Embrapa Clima Temperado. Circular técnica, 70).

CASTRO, L.A.S. de; RASEIRA, M. do C.B.; BARBOSA, W.; NAKASU, B.H. Ameixeira: cultivares indicadas para plantio nas regiões produtoras brasileiras. Pelotas: Embrapa Clima Temperado, 2008b. 16p. (Embrapa Clima Temperado. Circular técnica, 81).

FRANKEN, J.; CUSTERS, J.B.M.; BINO, R.J. Effects of temperature on pollen tube growth and fruit set in reciprocal crosses between Cucumis sativus and C. metuliferus. Plant Breeding, v.100, p.150-153, 1988.

GOLDWAY, M.; SHAI, O.; YEHUDA, H.; MATITYAHU, A.; STERN, R.A. 'Jonathan' apple is a lower-potency pollenizer of 'Topred' than 'Golden Delicious' due to partial S-allele incompatibility. Journal of Horticultural Science and Biotechnology, v.74, p.381-385, 1999.

GUERRA, M.E.; RODRIGO, J.; LÓPEZ-CORRALES, M.; WÜNSCH, A. S-RNase genotyping and incompatibility group assignment by PCR and pollination experiments in Japanese plum. Plant Breeding, v.128, p.304-311, 2009.

LEITE, D.L.; SOUZA, C.M. de. Polinização. In: CENTELLAS-QUEZADA, A.; NAKASU, B.H.; HERTER, F.G. (Ed.). Pêra: produção. Brasília: Embrapa Informação Tecnológica, 2003. p.23-28. (Frutas do Brasil, 46). 
MACHADO, A.A.; CONCEIÇÃO, A.R. WinStat: sistema de análise estatística para Windows. Versão 2.0. Pelotas: UFPel, 2003.

MOTA, M.S.; BIANCHI, V.J.; CARVALHO, A.Z. de; BRAGA, E.J.B.; PETERS, J.A. Caracterização molecular dos alelos-S de incompatibilidade gametofítica em Prunus salicina Lindl. Revista Brasileira de Fruticultura, v.32, p.798-807, 2010.

NAVA, G.A.; DALMAGO, G.A.; BERGAMASCHI, H.; PANIZ, R.; SANTOS, R.P. dos; MARODIN, G.A.B. Effect of high temperatures in the pre-blooming and blooming periods on ovule formation, pollen grains and yield of 'Granada' peach. Scientia Horticulturae, v.122, p.37-44, 2009.

POUND, L.M.; WALLWORK, M.A.B.; POTTS, B.M.; SEDGLEY, M. Pollen tube growth and early ovule following self and cross-pollination in Eucalyptus nitens. Sexual Plant Reproduction, v.16, p.59-69, 2003.

RASEIRA, M.C.B. Polinização. In: CASTRO, L.A.S. de (Ed.). Ameixa: produção. Brasília: Embrapa Informação Tecnológica, 2003. p.30-33. (Frutas do Brasil, 43).

REVERS, L.F.; MACHADO, C.A.E. Identificação varietal e genotipagem: serviços oferecidos pelo Laboratório de Biologia Molecular da Embrapa Uva e Vinho. Bento Gonçalves: Embrapa Uva e Vinho, 2005. 6p. (Embrapa Uva e Vinho. Comunicado técnico, 64)

RICHARDS, A.J. Plant breeding systems. London: George Allen \& Unwin, 1986. 528p.

SANZOL, J.; HERRERO, M. The "effective pollination period" in fruit trees. Scientia Horticulturae, v.90, p.1-17, 2001.
SAPIR G.; STERN, R.A.; EISIKOWITCH, D.; GOLDWAY, M. Cloning of four new Japanese plum S-alleles and determination of the compatibility between cultivars by PCR analysis. Journal of Horticultural Science and Biotechnology, v.79, p.223-227, 2004.

SCHIFINO-WITTMANN, M.T.; DALL'AGNOL, M. Auto-incompatibilidade em plantas. Ciência Rural, v.32, p.1083-1090, 2002.

SILVEIRA, T.M.T. de. Polinização em amoreira-preta (Rubus sp.), mirtilo (Vaccinium ashei) e ameixeira-japonesa (Prunus salicina). 2008. 90p. Dissertação (Mestrado) Universidade Federal de Pelota, Pelotas.

TAKAYAMA, S.; ISOGAI, A. Self-incompatibility in plants. Annual Review of Plant Biology, v.56, p.457-489, 2005.

THIELE, I.; STRYDOM, D.K. Incompatibility studies in some Japanese plum cultivars ( $P$. salicina L.) grown in South Africa. South African Journal of Agricultural Science, v.7, p.165-168, 1964.

THOMAS, S.G.; FRANKLIN-TONG, V.E. Self-incompatibility triggers programmed cell death in Papaver pollen. Nature, v.429, p.305-309, 2004.

VAN TONDER, M.J.; BESTER, C.W.J. Cross-pollination requirements of the plum Cultivar Redgold. Deciduous Fruit Grower, v.29, p.152-154, 1979.

WILSON, J.A.; BROWN, S.O. Differential staining of pollen tubes in grass pistils. Agronomy Journal, v.49, p.220-222, 1957.

ZHANG, Y.; ZHAO, Z.; XUE, Y. Roles of proteolysis in plant self-incompatibility. Annual Review of Plant Biology, v.60, p.21-42, 2009.

Recebido em 27 de maio de 2011 e aprovado em 10 de agosto de 2011

Pesq. agropec. bras., Brasília, v.46, n.8, p.860-867, ago. 2011 